\title{
Designing a Measure of Visual Selective Attention to Assess Individual Differences in Information Processing
}

\author{
Bruce J. Avolio, Ralph A. Alexander, \\ Gerald V. Barrett, and Harvey L. Sterns \\ The University of Akron
}

\begin{abstract}
A new method for determining individual differences in information processing was developed and illustrated. The measure, Visual Selective Attention, was constructed according to the parameters and specifications of a standardized measure of auditory selective attention. Emphasis was placed upon establishing the relationship of this new measure with traditional measures of information processing (i.e., perceptual style and selective attention). The results provided initial evidence for the reliability and validity of the new measure. Applications for Visual Selective Attention and interpretation of the findings are discussed in view of the current state of the information-processing literature. Implications for additional research focus upon the practical applications of the new measure.
\end{abstract}

The concern for individual differences in performance has grown dramatically in psychology. This growth is particularly evident with research using the Rod-and-Frame Test (RFT) developed by Witkin, Lewis, Hertzman, Machover, Meissner, and Wapner (1954). As reported by Goldberg (1979), the RFT was initially developed from the research focusing on spatial orientation. In later analyses the RFT was applied as an objective measure of personality. However, in the context described here, the RFT will be considered a measure of information processing (i.e., perceptual style).

APPLIED PSYCHOLOGICAL MEASUREMENT

Vol. 5, No. 1, Winter 1981, pp. 29-42

(c) Copyright 1981 Applied Psychological Measurement Inc.
Considering the work with the RFT in the last decade, there have been few major efforts afforded to the investigation of information-processing ability and how different abilities relate to "real world" behavior. Some notable exceptions to this generalization have been presented in the area of automobile accident involvement and aircraft flight performance (Barrett, Mihal, Panek, Sterns, \& Alexander, 1977; Gopher \& Kahneman, 1971; Kahneman, Ben-Ishai, \& Lotan, 1973; Mihal \& Barrett, 1976). Mihal and Barrett (1976) demonstrated the predictive validity of selective attention ability and perceptual style for determining those individuals involved in a higher proportion of accidents. These results were supported by Barrett, Mihal, $\mathrm{Pa}$ nek, Sterns, and Alexander (1977). Gopher and Kahneman (1971), who originally developed the Auditory Selective Attention Test (ASAT), demonstrated its utility in predicting aircraft flight performance. The accumulation of this research provided substantial support for auditory selective attention as a predictive tool in real world settings.

Recently, Barrett, Alexander, and Forbes (1977) combined measures of information-processing ability into an integrated model to facilitate the understanding of underlying processes associated with task performance. The model was comprised of components of informationprocessing ability (e.g., selective attention, per- 
ceptual style, reaction time). The course in the development of this model has been to identify or to construct measures of information processing that relate to other individual difference measures, as well as to the task at hand. This emphasis was demonstrated in the previous research of Mihal and Barrett (1976) and Barrett, Mihal, Panek, Sterns, and Alexander (1977). Combining different measures of information processing into a test battery, they demonstrated a moderate relationship between divergent information-processing measures, in addition to establishing a linkage between processing capacity for separate sensory modalities (i.e., vision versus hearing). As stated previously, both measures separately were predictive of accident involvement.

One important result noted above concerns the relationship in performance for different sensory modalities. Researchers have focused upon intersensory relationships in information processing, specifically with vision and hearing. However, these research efforts have tended to place a greater emphasis on measures of auditory versus visual selective attention. This trend may be partially attributed to Broadbent (1958) and Von Wright (1968), who cautioned researchers in conducting investigations with vision, due to the confounding nature of eye movement patterns. Consequently, very few measures of visual attention were developed. The overemphasis placed on auditory selective attention is evident in the theoretical models of information processing, which specifically focus upon auditory perception (e.g., Broadbent, 1957; Kahneman, 1973; Triesman, 1969).

Ironically, the emphasis placed upon developing measures of auditory information processing tends to minimize the importance that the visual modality demonstrates in influencing other sensory mechanisms (Colavita, 1971; Gibson \& Yonas, 1966; Kahneman, 1973; Pick, Warren, \& Hay, 1969; Rock \& Victor, 1964). Kahneman (1973) emphasized this point by indicating that the mere position of the eye may determine the direction of sensory attention.
The effects of vision on overall sensory performance seems to have been clearly demonstrated in past research. With this evidence accumulated, it seems questionable that an auditory measure of selective attention should be used to predict tasks requiring visual processing.

\section{Objectives}

The purpose of the present investigation was to develop a measure of visual selective attention that correlates with existing measures of information-processing ability. If moderate correlations are obtained between traditional measures of information-processing ability (e.g., auditory selective attention and perceptual style) and a newly constructed measure of visual selective attention, then initial evidence for the construct validity of this measure would be established. A moderate correlation would be desirable, since the ultimate goal was to use this new measure with other traditional measures to increase the predictive validity of the test battery for real world performance.

An intermediate objective of this investigation was to supplement the existing literature pertaining to a central processing mechanism that coordinates information-processing performance. For instance, Birch and Lefford (1967) indicated that the existence of a monitoring system that accumulates data across multiple sensory channels was highly probable. Evidence to support this contention was provided by Fisher and Rubenstein (1975a, 1975b). These researchers demonstrated a significant relationship between visual and auditory processing which increased with age. Support for a central mechanism has also come from additional research (Forbes, Barrett, Alexander, \& Phillips, 1976; Gopher, 1971; Kahneman, 1973; Webster \& Haselrud, 1964).

To summarize, this investigation had two specific goals. The primary objective was the development of a reliable measure of visual selective attention that can be used in future investigations to predict individual differences in "real 
world" performance. A secondary objective was to provide additional evidence for the existence of a central processing mechanism.

\section{Method}

\section{Subjects}

Sixty university student volunteers from a large midwestern city participated in the study. The group was comprised of 30 males and $30 \mathrm{fe}-$ males. The students' ages ranged from 18 to 26 . All students were selected from a university population and were in good health.

\section{Experimental Tests}

There were six relevant measures administered to the group of students, although only four will be analyzed in this report. The Group Embedded Figures Test (GEFT) developed by Witkin, Oltman, Raskin, \& Karp (1971) was administered to all students. This test consists of three parts in which the subject extracts a relevant stimulus amidst an irrelevant background. The first part was a practice section to help familiarize the subject with the procedure. The next two sections were the test trials, which consisted of nine complex figures each. The subject was allowed 5 minutes to complete each test section. The subject's score equals the total number of figures correctly traced in both test sections.

The RFT Model V-1260-M2, from the Polymetric Company, was also used as a measure of perceptual style. The apparatus consists of a luminous rod surrounded by a luminous frame, which both rotate separately. This task was administered in a room that was specifically designed to decrease the effects of ambient light. The room was completely painted black with a black carpet on the floor. The doors were sealed to eliminate light. Each subject was administered the test as described by Witkin et al. (1954), while seated in a stationary tilting chair (Model No. 18-20 Marietta Apparatus Company). The chair was placed directly in front of the apparatus at a distance of 3 meters.
Throughout the presentation, the rod and frame were at the initial starting positions of $28^{\circ}$ left or right.

The procedure for setting the apparatus was standard across trials. The experimenter moved the rod in increments of $3^{\circ}$ each time the subject responded. The subject stopped the experimenter when the rod appeared vertical. After every eighth trial the subject was placed upright for a duration of 1 minute with eyes closed before continuing on to the next series. The subject's score was computed by the average number of degrees of error for the three series.

The ASAT (Mihal \& Barrett, 1976) presents 24 dichotic messages simultaneously to the subject's ears with volume adjusted for individual hearing levels. Each dichotic message was broken down into two parts consisting of a series of pairs of numbers and letters. The initial portion of the tape informed the subject of the nature of the test and his/her responsibilities. After completion of the instructions, there were four practice messages to help familiarize the subject with the procedure. The practice and 24 test messages were based on the following framework.

Each message began with a verbal announcement of the message number, which the subject reported to the experimeter. After the voice on the tape had indicated the message number, there was a 2.5 -second interval before the relevant tone was initiated. The relevant tone was presented for 200 milliseconds. A $2500 \mathrm{~Hz}$ tone indicated that the information on the right ear channel was relevant. A $250 \mathrm{~Hz}$ tone indicated that the left ear channel was relevant. It is important to note that both channels were presented simultaneously; therefore, the tones indicated which channel to attend to and which to ignore for each part of the message once the tone had been presented. There was a 1.5 -second gap before 16 pairs of numbers and letters were presented. These pairs were presented at a rate of two per second. Each pair consisted of either single English letters and/or digits ranging from 0 to 9 (e.g., B 8). After the 16 pairs were presented (i.e., Part 1), there was a 1.5-second inter- 
val before the relevant tone was presented for Part 2 of the message. The relevant tone (i.e., $2500 \mathrm{~Hz}$ or $250 \mathrm{~Hz}$ ) was presented for 200 milliseconds. After the tone was terminated, a 1.5second interval followed before the presentation of pairs comprising Part 2 of the message.

The second part of each message contained three pairs of numbers, which were preceded by either 0,1 , or 2 additional pairs of letters. Following the presentation of the last pair in Part 2, there was a 5-second interval to allow the subject to prepare for the presentation of the next message number.

The subject's task for both Parts 1 and 2 of each message was to report aloud the digits appearing on the channel that was indicated as being relevant. For Part 1 of all 24 messages, the relevant channel had either 2 or 4 relevant digits, while the irrelevant channels always had 6 digits. For Part 2 of each message there were always 3 relevant and 3 irrelevant digits presented.

The scoring procedure for the ASAT consisted of omission and intrusion errors. An omission error was scored when the subject failed to report a digit from the relevant channel. An intrusion error was indicated when the subject reported a digit from the irrelevant channel. The reporting of letters was very infrequent and therefore not considered an intrusion error. The subject's overall score was comprised of total omission and intrusion errors across the 24 messages.

The ASAT was presented on a Sony Solid State Tape recorder, Model TC-353. The headphones were Pickering stereo headphones Model PH-4933. The presentation of the messages was set at a level of amplification that was comfortable for each subject.

A Visual Selective Attention Test (VSAT) was constructed to approximate a visual counterpart of the ASAT. The test was presented to subjects through a Tektronix CRT screen Model No. 4010 linked to a PDP $11 \mathrm{E} 10$ computer. The characters appearing on the screen were numbers and letters. The size of the characters was 3 $\mathrm{mm}$. (.58 visual angle subtended), which is in accord with Purcell, Stanovich, and Spector (1978) specifications. The pairs of numbers and letters were presented in the center of the screen. Each of the characters making up the pairs were presented at $7.5 \mathrm{~mm}$. on either side of the center point of the screen. The major differences between the auditory and visual measures of attention were in the requirements of the subjects and the pace of each test. With the auditory test, subjects attended to the left or right channel depending on the cue. Rather than split an individual's field of vision, which does not represent normal visual processing, it was felt that having subjects respond to particular stimuli in both the left and right channel would allow for a more accurate assessment of actual visual processing. This difference in methodology undeniably places some constraints on the conclusions.

Another difference was in the pace at which the stimuli were presented. With the ASAT the pace of presentation was constant across messages. With VSAT the speed of presentation was systematically decreased across trials to evaluate the upper range of individual ability. Neither of these differences was expected to have a major impact on the analysis of the relationship between visual selective attention, auditory selective attention, and perceptual style.

The subjects were instructed on the nature of the test and located approximately $30 \mathrm{~cm}$. from the screen. After the instructions, the subjects received four practice trials to help familiarize them with the procedure. After the practice trials ended, the test messages began. There were 24 test messages consisting of two parts each. The practice trials followed the same format as the test messages; therefore, a description of the test format will suffice.

At the beginning of each message, the message number was presented and then erased. After a 2.5 second interval, the relevant cue word was presented for half a second. The cue words coffee and apple were chosen to correspond with the relevant cues of an alternative measure of auditory attention not reported here. The cue word coffee indicated for the subject to respond to all odd numbers in the left channel and even 
numbers in the right. The word apple indicated that even numbers in the left channel and odd in the right were to be reported. The instructional set forced the subject to attend to both channels, therefore approximating normal visual processing. Memory factors were eliminated by sufficient practice of the instructional set.

The cue words were presented on either side of the midpoint of the screen to control for a position effect. Following the erasure of the cue word, there was a 2-second interval before Part 1 of the message was presented. Part 1 consisted of 16 pairs, each pair consisting of either an English letter and number, two English letters, or two numbers. The numbers ranged from 0 to 9 , with the exclusion of the number 8 due to its similarity with the letter $B$.

Following the erasure of the last pair of Part 1, there was a 2-second interval before the presentation of the word for Part 2 of the message. After the cue word was erased, there was a 2 -second interval before the presentation of the second set of pairs. The second part of each message always contained pairs of digits. These pairs were preceded by either 0,1 , or 2 additional pairs of letters. Following the completion of Part 2, there was a 5-second interval before the presentation of Message Number 2, which allowed the subjects to prepare for the next message.

The format of the test, summarized in Table 1, called for a decrease of 50 milliseconds (msec) in the presentation of each pair following every third message. Consequently, each pair in the first three messages was displayed on the screen for $400 \mathrm{msec}$; the next three messages presented each pair at a rate of $350 \mathrm{msec}$ per pair. Following this pattern across the 24 messages, the last three messages presented each pair for a period of $50 \mathrm{msec}$. All other specifications for the VSAT were set as close as possible to those used by the ASAT. Scoring was also based upon the same procedure used in the auditory test (i.e., omission and intrusion errors).

\section{Procedure}

All subjects were tested individually under the same conditions. At the beginning of the experiment, each subject had a detailed explanation of the purpose of the experiment. The total sample of individuals was partitioned into subgroups. Subjects were assigned to groups ran domly with equal numbers of males and females in each group (e.g., five and five). The purpose of partitioning the subjects into groups was to counterbalance for order effects. To control order effects, the critical tests of the hypotheses (i.e., ASAT and VSAT) were presented to each group in several possible positions to counterbalance for order. The critical tests were separated in the administration of the battery by four other test measures (i.e., Competing Messages Test, RFT, Pace of Information Flow, and GEFT). One-way analyses of variance to test for order effects did not yield any significant effects. There were no values that were even marginally significant. The separation of critical tests in time also helped to minimize fatigue effects. Additional analyses for differences due to the sex of the subject did not reveal any significant trends; therefore, correlational analyses and conclusions were based on the overall sample and the four measures of interest (i.e., VSAT, ASAT, GEFT, RFT).

\section{Results}

Means and standard deviations are presented in Table 2 for the computed scores for each information-processing measure. The data indicated some restriction in range with the scores acquired. These findings may be attributed to the ages of the subjects, that is, younger individuals often perform better on measures of information processing (Panek, Barrett, Sterns, \& Alexander, 1978).

The major intention was to investigate the establishment of a new measure of selective attention. Nunnally (1978) has suggested that all new 
Table 1

Message Format Summary for Visual and Auditory Selective Attention

\begin{tabular}{l} 
Message Scheme \\
\hline 1. Message number presented \\
2. Time interval between message \\
number termination and rele- \\
vant cue
\end{tabular}

3. Relevant cue for Part 1

4. Time interval following relevant cue termination and Part 1 onset

5. Part 1

6. Time interval following the termination of the last pair and the relevant cue for Part 2

7. Relevant cue for Part 2

8. Time interval following relevant cue termination and Part 2 onset

9. Part 2

10. Time interval following the termination of Part 2 and the onset of the next message number

measures should be tested for their reliability; therefore, tests for internal consistency were conducted using coefficient alpha. This statistic was the most appropriate indication of reliability based on the design of the selective attention measures. The reliability estimates are presented in Table 3 . The reliability estimates for the VSAT indicated that this measure obtained consistent responses to the stimulus presentations throughout the task. The consistency in responding provided some evidence for the reliability of this measure.

VSAT

Visualiy

\section{5 seconds}

coffee or apple (.5 seconds)

16 pairs of numbers and letters presented one pair at a time sequentially (Time duration varies)

2 seconds

coffee or apple (.5 seconds)

2 seconds

3 pairs of numbers and letters preceded by 0,1 , or 2 additional pairs of letters

5 seconds
ASAT

Audi tority

2.5 seconds

puretone $2500 \mathrm{~Hz}$

or $250 \mathrm{~Hz}(.5$

seconds )

1.5 seconds

16 pairs of numbers and letters presented one pair at a time sequentially (8 second duration)

2 seconds

pure tone $2500 \mathrm{~Hz}$ or $250 \mathrm{~Hz}(.5$ seconds)

1.5 seconds

3 pairs of numbers and letters preceded by 0,1 , or 2 additiona? letters

5 seconds
Pearson product-moment correlations were computed between total scores on all of the tests in the battery. Table 4 presents the results of these analyses. The relationship between the measures of selective attention yielded a significant positive correlation. VSAT also related significantly to the GEFT. The relationship with the RFT was not significant. A significant negative relationship between the VSAT and the GEFT was obtained, since the attention measures were based on total incorrect, whereas the GEFT was total correct. 
Table 2

Means and Standard Deviations for

Computed Information-processing Scores

\begin{tabular}{crr} 
& $(\mathrm{n}=60)$ & \\
\hline Test, Part \& Score & $M$ & SD \\
\hline VSAT & & \\
Part 1 & 4.90 & 7.71 \\
Omissions & 6.75 & 6.64 \\
Intrusions & 11.65 & 12.74 \\
Total & 11.20 & 11.00 \\
Part 2 & 5.40 & 4.53 \\
Omissions & 16.60 & 13.12 \\
Intrusions & & \\
Total & 7.33 & 4.60 \\
ASAT & 3.43 & 3.20 \\
Part 1 & 10.76 & 6.53 \\
Omissions & & \\
Intrusions & 9.52 & 8.53 \\
Tota 1 & 4.10 & 3.42 \\
Part 2 & 13.62 & 10.73 \\
Omissions & & \\
Intrusions & 13.05 & 4.91 \\
Total & 8.41 & 6.44 \\
GEFT & 8.80 & 7.03 \\
Total Correct & 5.20 & 4.94 \\
RFT & & \\
Series 1 & & \\
Series 2 & & \\
Series 3 & & \\
\hline
\end{tabular}

To further analyze the relationship between auditory and visual attention measures, the component scores from each were computed and correlated (see Table 5). Partitioning the total scores resulted in patterns of correlations that aided in clarifying the relationship of these two measures. Comparing the intercorrelations between the two measures for Parts 1 and 2, the relationships among intrusion errors were consistently low and nonsignificant, whereas omission errors demonstrated a higher frequency of significant relationships with each other. This pattern may result from the subjects' reluctance to generate responses they were unsure of (i.e., intrusion errors) versus having responses go by that they were unprepared to initiate (i.e., omission errors), therefore decreasing the amount of variance in intrusion error scores that could attenuate the correlations.

Another interesting pattern of correlations arose from the relationships between Parts 1 and 2 across the two measures of attention. For Part 2 of the auditory measure, the omission and total error scores correlated significantly with corresponding scores of the visual attention measure more frequently and higher than Part 1 component scores. This pattern was true for both parts of the VSAT. Overall, Part 2 omis- 


\begin{tabular}{l} 
Table 3 \\
Tests for Internal Consistency on the \\
Selective Attention Measures Using Coefficient Alpha \\
\hline Selective Attention Variables
\end{tabular}

sion scores exhibited higher correlations, for both measures, than those of Part 1. An explanation for this finding is given below.

The intercorrelations of subscores within each test demonstrated consistently high significant relationships. Relationships involving intrusion error scores were often somewhat lower than those demonstrated between omission error scores, although still significant in most cases. Again, the lower correlations demonstrated by intrusion error scores may be partially attributed to the nature of the score and the rationale previously discussed. Overall, the intercorrelations within the specific measures were consistently strong and in the positive direction.
To determine whether the relationships between component scores for the attention measures would correlate significantly with scores from the perceptual style measures, additional analyses were conducted. The results from these analyses, summarized in Table 6 , did not vary substantially from those displayed with total overall scores for the attention measures. Again, omission errors for the ASAT did provide higher correlations with the measure of interest; however, this pattern was not evident in the first part of the VSAT. Also of interest is the lack of significance demonstrated with Series 3 of the RFT versus Series 1 and 2. In Series 3 the individual remained erect while the apparatus was manip-

Table 4

Correlations Among Total Scores

$(\mathrm{N}=60)$

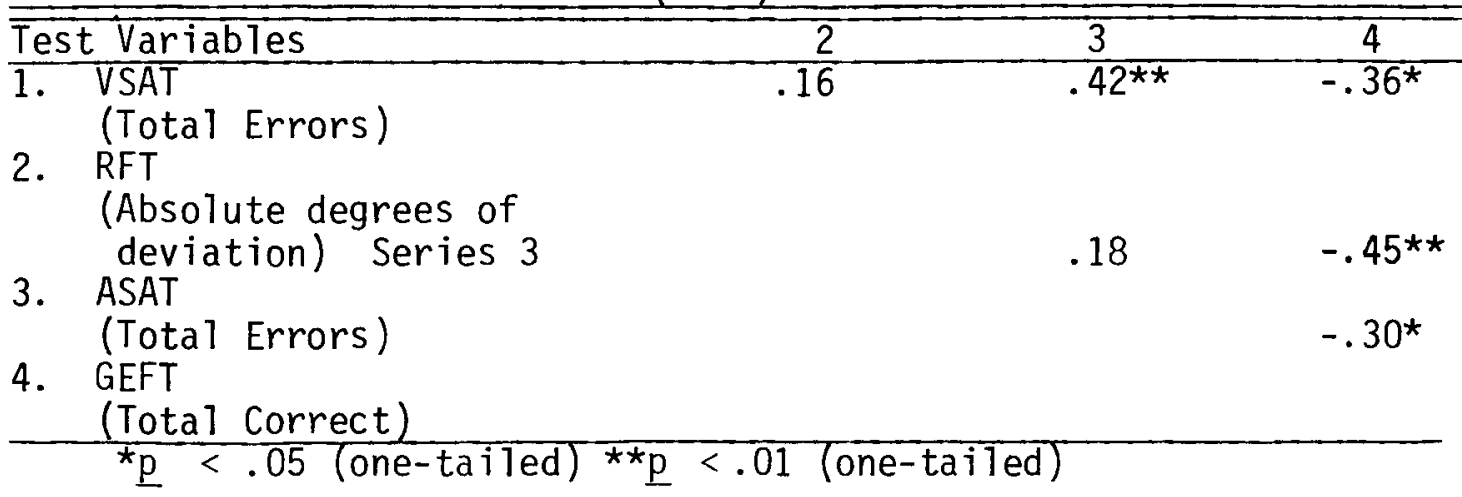




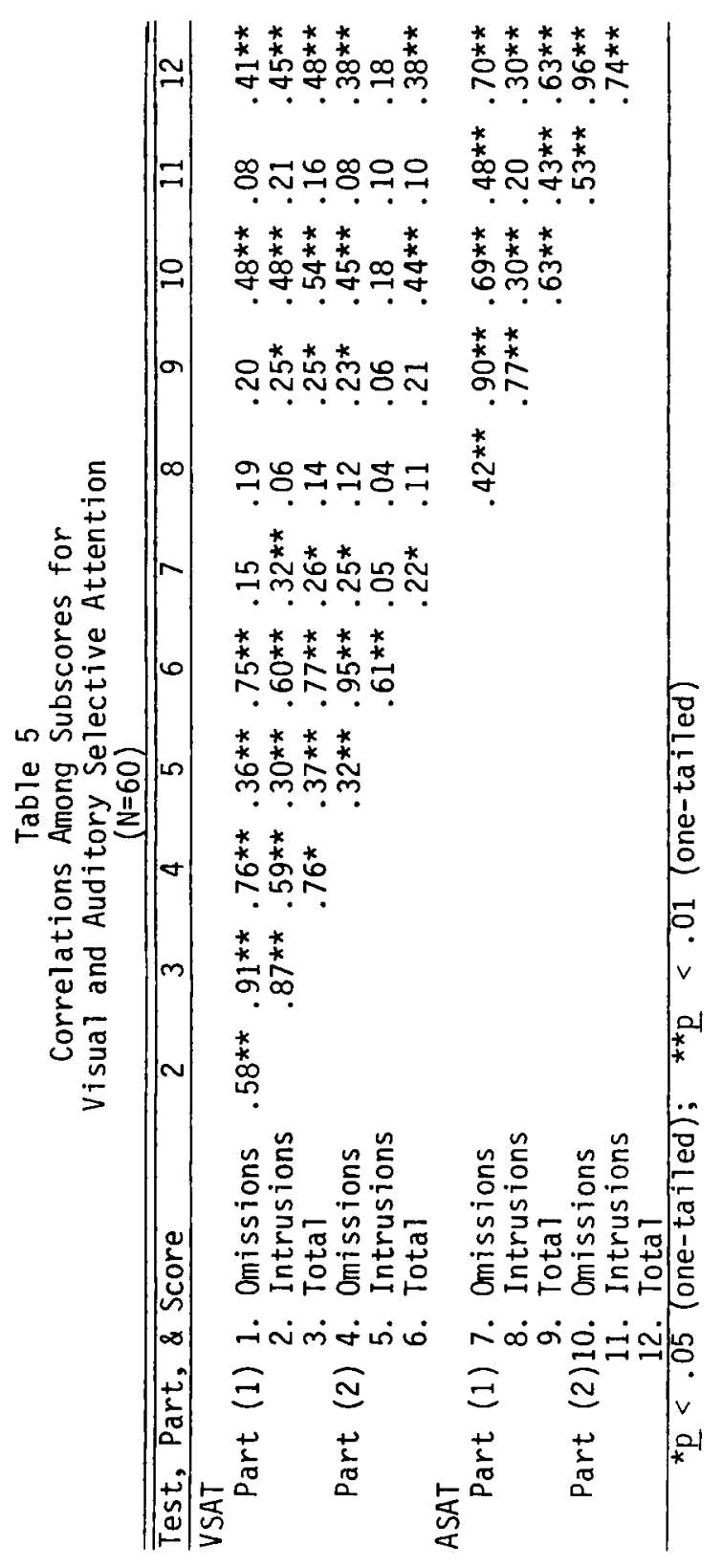

ulated. Varying the individual's bodily orientation (i.e., Series 1 and Series 2) showed a demonstrable effect on the relationship between perceptual style and selective attention. Perhaps the increased difficulty in performing Series 1 and 2 contributed to the relationships in component scores between selective attention and perceptual style.

These data show that the VSAT correlated with measures of auditory selective attention and perceptual style. These results provide some evidence for the construct validity of this new measure in assessing individual differences in information processing.

A power analysis was conducted to determine the number of subjects necessary to achieve significance for testing differences between dependent correlation coefficients (i.e., Hotellings $T$ test analyzing $r_{12}$ versus $r_{13}$, given $r_{23}$ ), given a potentially moderate effect size (i.e., 30). With this effect size a sample of $\mathbf{5 7}$ subjects was required to obtain a two-thirds probability of rejecting the null hypothesis, given that the alternative was true for a one-tailed test of significance at a .05 level (Cohen, 1969, Table 4.4.1, p. 130). Consider the null hypothesis as stating no difference in correlations between the selective attention measures (i.e., Variables 1 and 2) versus their relationship with measures of perceptual style (i.e., Variable 3). The alternative hypothesis indicated that measures of selective attention had significantly higher relationships with each other than their corresponding relationships with perceptual style. The results of the tests for dependent correlation coefficients are presented in Table 7.

Since the attention measures were supposedly tapping the same construct, it was expected that these measures would relate significantly higher with each other than their corresponding relationships with the remaining tests in the battery. The results partially supported this contention. The VSAT did correlate highly with the auditory measure; however, this correlation was not significantly higher than the one obtained between VSAT and the GEFT. With the RFT the alternative hypothesis was supported. 


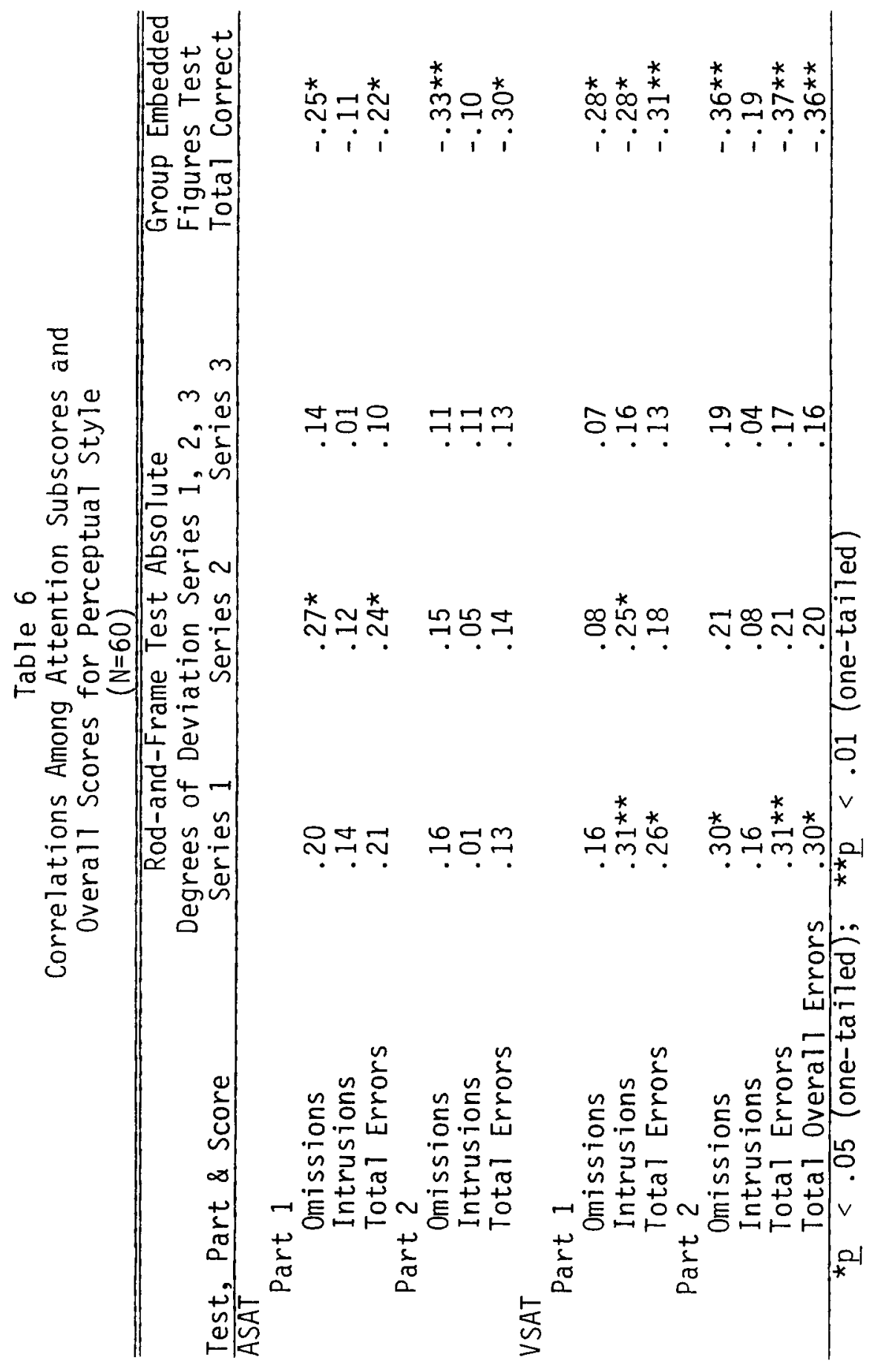




\section{Table 7}

T-tests for Dependent Correlation Coefficients Comparing the Relationships Between Total Score for Selective Attention and Perceptual Style

\begin{tabular}{|c|c|c|c|c|c|c|c|}
\hline $\operatorname{Var} 1$ & $\operatorname{Var} 2$ & $\operatorname{Var} 3$ & $\begin{array}{l}\operatorname{Var} 1 \\
\text { Vs } \\
\text { Var } 2 \\
r_{12}\end{array}$ & $\begin{array}{l}\operatorname{Var} 1 \\
\text { Vs } \\
\operatorname{Var} 3 \\
r_{13}\end{array}$ & $\begin{array}{l}\operatorname{Var} 2 \\
\text { vs } \\
\operatorname{Var} 3 \\
r_{23}\end{array}$ & $\begin{array}{c}t \\
\text { Value } \\
(d f=57)\end{array}$ & $\begin{array}{c}\text { P- } \\
\text { Value } \\
\text { One- } \\
\text { tailed }\end{array}$ \\
\hline $\begin{array}{l}\text { VSAT } \\
\text { VSAT }\end{array}$ & $\begin{array}{l}\text { ASAT } \\
\text { ASAT }\end{array}$ & $\begin{array}{l}\text { GEFT } \\
\text { RFT (Series } \\
3 \text { ) }\end{array}$ & $\begin{array}{l}.42 \\
5.42\end{array}$ & $\begin{array}{r}-.36 \\
.16\end{array}$ & $\begin{array}{r}-.30 \\
.18\end{array}$ & $\begin{array}{r}.44 \\
1.69\end{array}$ & $\begin{array}{l}.50 \\
.05\end{array}$ \\
\hline
\end{tabular}

Thus, the VSAT did correlate significantly higher with a similar measure of attention versus its relationship with one measure of perceptual style. Since the VSAT did relate to all measures, it might be concluded that it was sampling abilities across several domains (e.g., visual attention, auditory attention, perceptual style).

\section{Discussion}

The results obtained confirmed the relationship between visual and auditory selective attention and emphasized the reaffirmation of past literature concerning the existence of individual differences in information processing (i.e., Barrett, Alexander, \& Forbes, 1977; Barrett, Cabe, \& Thornton, 1968; Barrett, Mihal, Panek, Sterns, \& Alexander, 1977; Forbes \& Barrett, 1978; Gopher \& Kahneman, 1971; Kahneman et al., 1973; Mihal \& Barrett, 1976). The results reconfirmed individual differences in information-processing ability.

As previously indicated, there were differences between Part 1 and Part 2 errors for both attention tests and between their respective relationships with perceptual style. An explanation for these findings comes from Gopher and Kahneman (1971), where Part 2 omission and intrusion errors were represented as being more reliable and valid predictors of performance. In explaining this finding the authors attributed the differences to a reconsideration of selective orienta- tion from the first half of each message to the second.

Through these changes in selective orientation, the second portion of each message provided a more valid estimate of selective attention ability. Gopher (1971) provided additional evidence for the change in selective orientation, which corresponds in shifts from Part 1 of each message to Part 2. The importance of Gopher's results arises from the modality which was explored (i.e., vision); the results provided evidence for variations in selective orientation being associated with changes in visual focal attention. Gopher's findings generalized the concept of shifts in selective orientation across sensory modalities. Based on those results, the use of the VSAT in a real world setting could contribute to predictive capacity in determining one's ability to rapidly shift selective orientation.

The results indicated that significant relationships existed between various information-processing measures, supporting the existence of a central processing mechanism. However, the two selective attention tests did not relate significantly higher with each other than their relationships with the GEFT. This finding can be explained by the earlier comments of Witkin, Goodenough, and Oltman (1977). In their initial conception both the RFT and GEFT were considered similar measures of the same construct (i.e., individual differences in disembedding ability in perception or field dependence-inde- 
pendence). The ability to disembed perceptually was shown to be related with intellectual activities, cognitive functioning, and overall structuring competence. Research further incorporated a wide array of spatial-visual cognitive factors into the dimension of field dependence-independence. The result of this consistent line of research indicated that the processes involved in the RFT and GEFT may not be isomorphic, resulting in differing relationships between these and other information-processing measures. This pattern may also indicate differential components existing within cognitive structures that are related but that allow for the processing of input from divergent channels (i.e., visual and auditory).

Another possible reason for the VSAT not being correlated significantly higher with the auditory attention measure may be attributed to visual dominance on task performance. In reviewing the literature, research concerning the effect of vision on sensory performance indicated that the visual modality can affect perception in other sensory modalities (e.g., Kahneman, 1973; Pick et al., 1969; Rock \& Victor, 1964). If vision contributed a dominating effect to performance, then obtaining differences between tasks dependent on the visual modality (i.e., RFT and VSAT) seems highly unlikely. Additional support for this contention comes from the low relationship between auditory attention and perceptual style.

The other area of concern relates to the format for the VSAT, which was based upon an auditory measure used by Mihal and Barrett (1976). Using this measure (which has been shown to be predictive of selective attention ability) as a model, the results displayed the potential for using VSAT as an alternative measure of selective attention ability. Several inferences can be made based on these results. Since auditory selective attention has been shown to be related to accident involvement and pilot competency (Barrett, Alexander, \& Forbes, 1977; Barrett, Mihal, Panek, Sterns, \& Alexander, 1977; Go- pher \& Kahneman, 1971; Mihal \& Barrett, 1976; Kahneman et al., 1973; Thornton et al., 1968; Trankell, 1959), and the VSAT was related to a measure of auditory attention, the use of both measures in a diagnostic battery may result in an increment in predictive validity.

Further evidence for the use of the VSAT in real world settings comes from its relationship with perceptual style. Abilities indicative of perceptual style also have been shown to be related to accident involvement and monitoring performance (Barrett, Alexander, \& Forbes, 1977; Barrett, Mihal, Panek, Sterns, \& Alexander, 1977; Barrett \& Thornton, 1968; Barrett, Thornton, \& Cabe, 1969; Forbes \& Barrett, 1978; Harano, 1970; Mihal \& Barrett, 1976), therefore providing additional evidence for the use of VSAT combined in a diagnostic battery with other information-processing tests to predict real world behavior.

Based on previous literature, McDonnell and Perusse (1974) have been the only other authors to attempt construction of a visual analog of an auditory attention measure. An important difference in their design and the design in the present study involves the process of validation. The present study modeled the visual test after an accepted auditory measure of attention shown to be predictive of performance in real world settings, whereas McDonnell and Perusse chose to construct both tasks based upon their own parameters rather than comparing them to an alternative measure of information processing (i.e., ASAT).

To summarize, a reliable test of Visual Selective Attention was developed based upon the specifications presented by Mihal and Barrett (1976). Based on these results, the next logical phase for use of this new measure would be to determine its applicability for predicting real world performance (e.g., driving performance). If this new measure provides increments in accountable variance over existing informationprocessing tests, further use of the measure in more diverse settings could be warranted. 


\section{References}

Barrett, G. V., Alexander, R. A., \& Forbes, J. B. Analysis of performance measurement and training requirements for driving decision-making in emergency situations. JSAS Catalog of Selected Documents in Psychology, 1977, 7, 126. (Ms. No. 1623).

Barrett, G. V., Mihal, W. L., Panek, P. E., Sterns, H. L., \& Alexander, R. A. Information-processing skills predictive of accident involvement for younger and older commercial drivers. Industrial Gerontology, 1977, 4, 173-182.

Barrett, G. V., Cabe, P. A., \& Thornton, C. L. Visual functioning and embedded figures test performance. Perceptual and Motor Skills, 1968, 26, 40.

Barrett, G. V., \& Thornton, C. L. The relationship between perceptual style and driver reaction time to an emergency situation. Journal of Applied Psychology, 1968, 52, 169-176.

Barrett, G. V., Thornton, C. L., \& Cabe, P. A. Relation between embedded figures test performance and simulator behavior. Journal of Applied Psychology, 1969, 53, 253-254.

Birch, H. G., \& Lefford, A. Visual differentiation, intersensory integration, and voluntary motor control. Monographs of the Society for Research in Child Development, 1967, 32 (Serial No. 110)

Broadbent, D. E. A mechanical model for human attention and immediate memory. Psychological Review, 1957, 64. 205-215.

Broadbent, D. E. Perception and communication. Oxford: Pergamon Press, 1958.

Cohen, J. Statistical power analysis for the behavioral sciences. New York: Academic Press, 1969.

Colavita, F. B. Interspecies differences in sensory dominance. Paper presented at the 12th annual meeting of the Psychonomic Society, St. Louis, November 1971.

Fisher, L., \& Rubenstein, G. Developmental aspects of auditory and visual scanning. Perceptual and Motor Skills, 1975, 40, 584-586. (a)

Fisher, L., \& Rubenstein, G. Sensory integration and single-modality scanning. Perceptual and Motor Skills, 1975, 40, 639-644. (b)

Forbes, B. J., \& Barrett, G. V. Individual abilities and task demands in relation to performance and satisfaction on two repetitive monitoring tasks. Journal of A pplied Psychology, 1978, 63, 188-196.

Forbes, B. J., Barrett, G. V., Alexander, R. A., \& Phillips, J. S. Organizational policy decisions as a function of individual differences and task design: Monitoring tasks (Technical Report No. 9). University of Akron, Department of Psychology, August 1976.
Gibson, E. J., \& Yonas, A. A developmental study of the effects of visual and auditory interference on a visual scanning task. Psychonomic Science. 1966, $5,163-164$.

Goldberg, L. R. A general scheme for the analytic decomposition of objective test scores: Illustrative demonstrations using the Rod-and-Frame Test and the Muller-Lyer Illusion. Journal of Research in Personality, 1979, 13, 245-265.

Gopher, D. Patterns of eye movement in auditory tasks of selective attention. Unpublished doctoral dissertation, Hebrew University, Jerusalem, 1971.

Gopher, D., \& Kahneman, D. Individual differences in attention and the prediction of flight criteria. Perceptual and Motor Skills, 1971, 33, 1335-1342.

Harano, R. M. Relationship of field-dependence and motor-vehicle-accident involvement. Perceptual and Motor Skills, 1970, 31, 272-274.

Kahneman, D. Attention and effort. Englewood Cliffs, NJ: Prentice-Hall, 1973.

Kahneman, D., Ben-Ishai, R., \& Lotan, M. Relation of a test of attention to road accidents. Journal of Applied Psychology. 1973, 38, 113-115.

McDonnell, P. M., \& Perusse, S. Selective attention in hearing and vision. Perception, 1974, 3, 221-230.

Mihal, W. L., \& Barrett, G. V. Individual differences in perceptual information-processing and their relation to automobile accident involvement. Journal of Applied Psychology, 1976, 61, 229-233.

Nunnally, J. C. Psychometric theory. New York: McGraw-Hill, 1978.

Panek, P. E., Barrett, G. V., Sterns, H. L., \& Alexander, R. A. Age differences in perceptual style, selective attention, and perceptual-motor reaction time. Experimental Aging Research, 1978, 4, 377-387.

Pick, H. L., Warren, H. D., \& Hay, J. C. Sensory conflict in judgments of spatial direction. Perception and Psychophysics, 1969, 6, 203-205.

Purcell, D. G., Stanovich, K. E., \& Spector, A. Visual angle and the word superiority effect. Memory and Cognition, 1978, 6, 3-8.

Rock, I., \& Victor, J. Vision and touch: An experimentally created conflict between the two senses. Science, 1964, 143, 594-596.

Thornton, C. L., Barrett, G. V., \& Davies, J. A. Field independence and target identification. Human Factors, 1968, 10, 493-496.

Trankeli, A. The psychologist as an instrument of prediction. Journal of Applied Psychology, 1959, 43, 170-175.

Triesman, A. M. Strategies and models of selective attention. Psychological Review, 1969, 76. 282-299. 
Von Wright, J. M. Selection in visual immediate memory. Quarterly Journal of Experimental Psychology, 1968, 20, 62-68.

Webster, R. G., \& Haselrud, G. M. Influence on extreme peripheral vision of attention to a visual or auditory task. Journal of Experimental Psychology, 1964, 68, 269-272.

Witkin, H. A., Goodenough, D. R., \& Oltman, P. K. Psychological differentiation: Current status (Research Bulletin 77-16). Princeton, NJ: Educational Testing Service, 1977.

Witkin, H. A., Lewis, H. B., Hertzman, M., Machover, K., Meissner, P. B., \& Wapner, S. Personality through perception. New York: Harper, 1954.

Witkin, H. A., Oltman, P. K., Raskin, E., \& Karp, S. A. A manual for the Embedded Figures Test. Palo Alto, CA: Consulting Psychologists Press, 1971.

\section{Acknowledgments}

This paper was supported in part by the Andrus Foundation. Contract No. 223-822-0.375, and Personnel and Training Research Programs, Psychological Sciences Division, Office of Naval Research, under Contract No. N00014-75-C-0985, NR 151-377. This paper is based in part upon an unpublished master's thesis conducted by the first author.

\section{Author's Address}

Send requests for reprints or further information to Bruce J. Avolio, Psychology Department, The University of Akron, Akron, OH 44325. 